\title{
Changes in Serum Anticonvulsant Levels with Febrile Illness in Children with Epilepsy
}

\author{
Keith J. Goulden, Peter R. Camfield, Carol S. Camfield, John A.R. Tibbles, \\ Joseph M. Dooley, Albert D. Fraser, Kenneth W. Renton
}

\begin{abstract}
Changes in anticonvulsant serum levels during intercurrent illness may cause toxicity or decreased seizure control in children with epilepsy. We studied prospectively the effect of intercurrent illness and its treatment in 111 children being treated with $\mathrm{AC}$ monotherapy. Free fraction and total serum AC levels were determined when the child was well, on the fifth day of any illness with fever and one month after recovery. There were 55 episodes of febrile illness in 39 children during the study period. Twelve illnesses were associated with significant increases or decreases in serum AC levels; 7 children became clinically toxic; 1 child had increased seizures during illness. The mechanisms of $\mathrm{AC}$ level changes appeared to include interaction with antibiotics, with antipyretics or with viral illness. Amoxycillin and acetaminophen did not appear to interact with the AC's used. Physicians caring for children with epilepsy should be aware of the frequency and complexity of potential interactions between intercurrent febrile illness and anticonvulsant medication.

RÉSUMÉ: Modifications des taux sériques des anticonvulsivants chez les enfants épileptiques atteints d'une maladie fébrile Des modifications dans les taux sériques des anticonvulsivants (AC) pendant une maladie intercurrente peuvent mener à la toxicité ou à un amoindrissement du contrôle des crises chez les enfants épileptiques. Nous avons étudié de façon prospective les effets des maladies intercurrentes chez 111 enfants traités par monothérapie anticonvulsivante. La fraction libre et le taux sérique total des $\mathrm{AC}$ ont été déterminés quand l'enfant était en bonne santé, au cinquième jour de toute affection accompagnée de fièvre et un mois après la guérison. Il y a eur 55 épisodes de maladies fébriles chez 39 enfants pendant le temps de l'étude. Douze épisodes fébriles ont été associés à une augmentation ou à une diminution des taux sériques d'AC: 7 enfants sont devenues toxiques cliniquement; 1 enfant a eu une augmentation des crises consulsives pendant sa maladie. Les mécanismes de changement des taux d'AC semblent inclure l'interaction avec les antibiotiques, les antipyrétiques ou les maladies virales. L'amoxycilline et l'acétaminophène ne semblaient pas interagir avec les AC utilisés. Tout médecin traitant des enfants épileptiques devrait connaître la fréquence et la complexité des interactions possibles entre les maladies fébriles intercurrentes et la médication AC.
\end{abstract}

Can. J. Neurol. Sci. 1988; 15:281-285

Minor febrile illness may complicate the management of children with epilepsy. The seizure frequency may be increased, possibly due to a lowering of the seizure threshold by fever. Somnolence or vomiting due to the infection may be confused with drug toxicity. Alternately, there may actually be changes in anticonvulsant levels during illness. These may be due to an interaction with the fever itself, the virus causing illness, or the medication used to treat the illness. ${ }^{\prime}$ We report a prospective study of the effect of minor febrile illnesses on anticonvulsant levels in children with epilepsy.

\author{
METHOD \\ Patient Selection \\ Children with epilepsy from Nova Scotia and Prince \\ Edward Island followed by the I.W. Killam Hospital for \\ Children Seizure Clinic were studied. Inclusion criteria were: \\ 1. Anticonvulsant monotherapy \\ 2. A history of compliance with therapy \\ 3. Age less than 17 years \\ 4. Informed parental consent
}

\footnotetext{
From the Department of Pediatrics, Dalhousie University and I.W. Killam Hospital for Children (Drs. Goulden, Camfield, Camfield, Tibbles, Dooley); Department of Pathology, Dalhousie University and Toxicology Laboratory, Victoria General Hospital (Dr. Fraser); Department of Pharmacology, Dalhousie University (Dr. Renton), Halifax

Presented in part at Child Neurology Society Meeting, Boston, Massachusetts, U.S.A., October 1986.

Received January 12, 1988. Accepted in final form April 27, 1988.

Reprint requests to: Peter R. Camfield, M.D., I.W.K. Hospital for Children, 5850 University Ave., Halifax, N.S., Canada B3J 3G9
} 
5. Demonstration of consent by having at least one baseline anticonvulsant level drawn according to study protocol.

The children were studied for 8 months (6-10 months) including the winter of 1985-86.

Of the 1,000 active charts on children with epilepsy followed by the Division of Pediatric Neurology, 300 children were found to be on AC monotherapy. The families of the 300 children on monotherapy were contacted by mail at the beginning of the study period and responders were enrolled.

\section{Study Protocol}

All families had or were given a thermometer and instructions on its use. All were given fever control instruction. The use of acetylsalicylic acid (ASA) or any antipyretic medication was discouraged, both verbally and in writing. The use of acetaminophen was permitted. The family was instructed to seek their usual medical care and to contact us in the case of any illness with a temperature over 38.5 degrees centigrade. For each illness, a record was kept of temperature, symptoms, medication and medical care.

Venous blood samples were obtained as close to 2 hours after the morning dose of medication as possible (or 14 hours after the evening dose for once daily phenobarbital) on all regular clinic visits. The sampling time was chosen to be convenient for study participants who normally attend a morning clinic. With notification of an illness, additional levels were obtained with the same timing on the 5th day of illness and again one month later. Levels were also obtained at other times if possible from any patients with toxic symptoms.

A subset of frequently seen, very compliant patients was given 2 doses of acetaminophen $(15 \mathrm{mg} / \mathrm{kg} / \mathrm{dose})$ to take 5 days before and on the morning of a subsequent clinic visit (if they had been well for one month before this time). This was designed to confirm the lack of interaction between acetaminophen and anticonvulsant drugs. ${ }^{2}$

The study protocol was approved by our Hospital Ethics Committee.

\section{Level Determinations}

Serum was separated immediately and frozen for analysis; samples drawn at peripheral centres were separated there and then transported frozen.

Total levels of carbamazepine (CBZ), phenobarbital (PHB) and phenytoin (DPH) were measured by high performance liquid chromatography using a modification of the Soldin method. ${ }^{3}$ Total levels of valproate (VPA) and ethosuximide (ETH) were analyzed by enzyme immunoassay (EMIT). ${ }^{4}$ Free levels of CBZ, VPA and DPH were separated by ultrafiltration and analyzed by EMIT. ${ }^{4}$ For our laboratory the theoretical "therapeutic range" is: PHB: $80-150$ uMol/L. DPH: $40-80$ uMol/L. CBZ: 13-40 uMol/L. ETH and VPA uncertain.

\section{Statistical Methods}

The variability of serum levels within the same child over the study period was examined for CBZ, VPA and PHB by calculating "repeatability coefficients" for children with two determinations of drug level available (Table 1). There were insufficient patients for this calculation on DPH or ETH. Using the method suggested by Bland and Altmann, 5 the standard deviation of the differences between the two levels was
Table 1: Repeatability Coefficients

\begin{tabular}{lcccc}
\hline \hline Drug & $\begin{array}{c}\text { \# of } \\
\text { Patients }\end{array}$ & $\begin{array}{c}\text { Total Level } \\
(\mathbf{u M o l} / \mathrm{L})\end{array}$ & $\begin{array}{c}\text { Free Level } \\
(\mathbf{u M o l} / \mathbf{L})\end{array}$ & \% Free \\
\hline CBZ & 12 & 11.5 & 4.0 & $10 \%$ \\
VPA & 6 & 400 & 102 & $10 \%$ \\
PHB & 7 & 16 & & \\
\hline
\end{tabular}

calculated and then doubled to give a repeatability coefficient of 2 standard deviations. Apparent changes in total, free or percent free serum levels during illness were assessed against these coefficients as a simple test for significance. A significant change in level for a particular child was taken to be one that differed from the baseline determination for that child by more than the repeatability coefficient.

\section{RESULTS}

A total of 111 children were enrolled in the study, taking: CBZ (53), VPA (23), PHB (19), DPH (10), or ETH (6). One child on each of PHB and DPH was withdrawn because of drug toxicity; one on PHB, 2 on VPA and 3 on CBZ had a second drug added during the study period due to recurrent seizures.

Treatment was for febrile convulsions in 5, for epilepsy in 106. Predominant seizures types were: 46 generalized, 16 simple partial, 29 complex partial and 15 partial with secondary generalization. There were 51 males and 60 females. The average age was 10 years (range 6 mos. to 17 years).

\section{IIInesses}

There were 55 illness episodes in 39 children. In 54 of 55 (98\%) symptoms suggested viral involvement, in $18(33 \%)$

Table 2: Illness Episodes

\begin{tabular}{lccccc}
\hline \hline & CBZ & VPA & PHB & DPH & ETH \\
\hline Number of patients & 53 & 23 & 19 & 10 & 6 \\
Number with illness & 18 & 6 & 9 & 3 & 3 \\
$\begin{array}{l}\text { Illness episodes } \\
\text { Symptoms of viral }\end{array}$ & 25 & 9 & 13 & 4 & 4 \\
$\begin{array}{l}\text { infection } \\
\text { Symptoms of }\end{array}$ & 24 & 9 & 13 & 4 & 4 \\
$\quad$ bacterial infection & 10 & 0 & 6 & 0 & 2 \\
Antibiotics & 16 & 1 & 7 & 0 & 3 \\
Antipyretics & 23 & 8 & 12 & 4 & 2 \\
\hline
\end{tabular}

Table 3: Summary of Significant Changes in Anticonvulsant Levels with Illness

Number of illnesses $=55$

Number with clinical toxicity $=5(\mathrm{CBZ}$-Erythromycin 3 , VPA-ASA 1, DPH-virus 1)

Number with significant increase in levels without toxicity $=4(\mathrm{CBZ}$-Erythromycin 1 , CBZ-Trimethoprim/sulpha 2, VPA-virus 1)

Number with significant decrease in levels without more seizures $=3(\mathrm{CBZ}$-virus 2, VPA-virus 1$)$

Number with significant decrease in levels with more seizures $=2($ PHB-virus 2$)$ 
Table 4: Interaction between Carbamazepine and Erythromycin

\begin{tabular}{lcccc}
\hline \hline Patient & 1 & 2 & 3 & 4 \\
CBZ Dose (mg/kg/d) & 11 & 14 & 12 & 11 \\
CBZ Levels (uMol/L) @ & & & & \\
$\quad$ Baseline & 25 & 23 & 30 & 23 \\
$\quad$ Illness & 43 & 44 & 58 & 43 \\
$\quad$ Follow-up & & 29 & & \\
Toxic Symptoms? & Yes* & No & Yes & Yes \\
\hline
\end{tabular}

- all outside 2 S.D. (from Table 1)

* developed toxic symptoms after an increase in erythromycin dose

@ Total levels only; free levels and \% free unchanged

Table 5: Apparent Interaction between CBZ and Trimeth/Sulpha

\begin{tabular}{lll}
\hline Patient & 1 & 2 \\
CBZ Dose (mg/kg/d) & 5 & 11 \\
CBZ Levels (uMol/L) @ & & \\
Baseline: Total & 22 & 25 \\
$\quad$ Free & 3.6 & $4.3 * 1$ \\
$\quad \%$ Free & $16 \% * 2$ & $17 \%$ \\
IIIness: Total & 18 & 34 \\
Free & 4.8 & $8.6 * 1$ \\
\% Free & $27 \% * 2$ & $25 \%$ \\
\hline
\end{tabular}

* 1, 2: outside 2 S.D. (from Table 1)

@ Follow-up levels omitted as all had returned to baseline

possible bacteridl infection, and 17 had symptoms of both. Twenty-seven of $55(49 \%)$ were treated with antibiotics and 49 of $55(89 \%)$ were treated with acetaminophen. The breakdown by anticonvulsant drug is shown in Table 2 .

Table 3 summarizes significant changes in anticonvulsant levels that were seen. Changes in each of the anticonvulsants are noted below.

\section{Carbamazepine}

Eight children on CBZ had significant level changes and/or toxicity induced by: erythromycin (4), trimethoprim/sulphamethoxazole (2) and viral infection (2).

All four exposures to erythromycin resulted in a significant elevation in levels (Table 4). Patient 1 developed toxic symptoms after the dose of erythromycin was increased from 27 $\mathrm{mg} / \mathrm{kg} / \mathrm{d}$ to $55 \mathrm{mg} / \mathrm{kg} / \mathrm{d}$ (but did not have levels obtained again until after the symptoms had resolved); patient 2 had a low baseline level and tolerated the increase without toxic symptoms; and patients 3 and 4 had both symptoms and levels compatible with $\mathrm{CBZ}$ toxicity.

Two patients were exposed to trimethaprim/sulphamethoxazole with increases in their free levels of CBZ (Table 5), suggestive of displacement from binding sites.

Two children on CBZ developed a significant decrease in their total levels without any change in free levels or percentage free drug in association with a presumed viral illness. The first child had an upper respiratory illness and was treated with acetaminophen: the CBZ levels were $17 \mathrm{uMol} / \mathrm{L}$ total, 4.4 $\mathrm{uMol} / \mathrm{L}$ free $(26 \%$ free). One month later the equivalent levels were $33 \mathrm{uMol} / \mathrm{L}$ total, $5.3 \mathrm{uMol} / \mathrm{L}$ free $(16 \%$ free $)$. The second child had pharyngitis (no culture taken) and was treated with amoxicillin and acetaminophen: CBZ levels changed from 34 $\mathrm{uMol} / \mathrm{L}$ total and $7.5 \mathrm{uMol} / \mathrm{L}$ free $(22 \%$ free $)$ to $20 \mathrm{uMol} / \mathrm{L}$ total and $4.6 \mathrm{uMol} / \mathrm{L}$ free $(23 \%$ free). Follow-up levels were not obtained until three months later and were: $29 \mathrm{uMol} / \mathrm{L}$ total, $7.8 \mathrm{uMol} / \mathrm{L}$ free $(27 \%$ free). Apart from this patient, nine other children were exposed to amoxicillin with changes in CBZ levels within 2 standard deviations of baseline.

In addition to the 8 children mentioned above, there were 15 other children on $\mathrm{CBZ}$ who were exposed to acetaminophen during illness. Neither these children nor the 4 who took acetaminophen while well had any significant change in CBZ levels.

\section{Valproic Acid}

There were 3 exposures to VPA and ASA (despite previous warning against this combination). Two ASA exposures consisted of a few doses only, but the third involved 4 doses of 12 $\mathrm{mg} / \mathrm{kg} / 4$ hours apart. This child developed an acute toxic psychosis with hyperactivity and paranoia. He also had a marked tremor and truncal ataxia. These symptoms resolved without any change in the dose of VPA. ${ }^{6}$

One patient had a rise and one a fall in VPA levels with viral illness which persisted one month later (Table 6). The

\begin{tabular}{lcc}
\hline Table 6: Interaction between Valproate and Viral Illness & \\
\hline \hline Patient & 1 & 2 \\
VPA Dose $(\mathrm{mg} / \mathrm{kg} / \mathrm{d})$ & 23 & 25 \\
VPA Levels $(\mathrm{uMol} / \mathrm{L})$ & 938 & 234 \\
Baseline: Total & 167 & 10 \\
Free & $18 \%^{*}$ & $4 \%$ \\
$\%$ Free & $534^{*}$ & $1312^{*}$ \\
Illness: Total & $34^{*}$ & $231^{*}$ \\
Free & $6 \%^{*}$ & $18 \% \%^{*}$ \\
\% Free & $624^{*}$ & $1071^{*}$ \\
Follow-up: Total & $69^{*}$ & $150^{*}$ \\
$\quad$ Free & $11 \%^{*}$ & $14 \%^{*}$ \\
$\quad \%$ Free & 2 &
\end{tabular}

* outside 2 S.D. (from Table 1) compared with baseline

Table 7: Interaction between Phenobarbital and Viral Infection

\begin{tabular}{|c|c|c|c|c|}
\hline \multirow[b]{2}{*}{ Patient } & \multirow[b]{2}{*}{$\begin{array}{l}\text { PHB dose } \\
\text { ( } \mathrm{mg} / \mathrm{kg} / \mathrm{d})\end{array}$} & \multicolumn{3}{|c|}{ PHB Levels (uMol/L) } \\
\hline & & Baseline & Illness & Follow-up \\
\hline $\begin{array}{l}1 \\
2\end{array}$ & $\begin{array}{l}2.7 \\
3.2\end{array}$ & $\begin{array}{l}71 \\
82\end{array}$ & $\begin{array}{l}21 * \\
38^{*}\end{array}$ & $\begin{array}{c}14^{*} \\
\text { (taken off) }\end{array}$ \\
\hline
\end{tabular}

* outside 2 S.D. (from Table 1) compared to baseline

child whose level increased with illness had a baseline level repeated five months later (total $544 \mathrm{uMol} / \mathrm{L}$, free $69 \mathrm{uMol} / \mathrm{L}$ (13\% free)) which confirmed the previous change from baseline.

Five exposures to acetaminophen as the only antipyretic while on VPA and 3 exposures to acetaminophen plus VPA when well resulted in no significant changes in VPA levels.

\section{Phenobarbital}

Two compliant patients on PHB showed a decrease in levels from baseline during viral illness (Table 7) together with increased seizure frequency. The 9 other exposures to acetaminophen and PHB during illness and 4 exposures to acetaminophen and PHB when well resulted in no significant change in PHB level. 


\section{Phenytoin}

One patient developed DPH toxicity during viral illness. There was an increase in total level (to $180 \mathrm{uMol} / \mathrm{L}$ ) and a return to baseline one month later without any long term change in dose.

\section{Ethosuccimide}

There were no significant changes in ETH levels during 4 illnesses.

\section{Discussion}

Our prospective experience with 55 illness episodes in 111 children on anticonvulsant monotherapy indicates that minor febrile illnesses are often associated with changes in anticonvulsant levels. The potential for febrile illness to change anticonvulsant levels has recently been reviewed, 1 and there are many potential mechanisms.

Minor infectious illness occurs frequently in childhood. Population studies suggest an incidence of 3-8 respiratory infections per year. ${ }^{7.8}$ The Junior Village study ${ }^{9}$ studied children in a nursery school setting and found a new febrile illness (bacterial or viral) every 5 weeks.

Concern about the increased risk of seizures with fever, may lead to enthusiastic treatment of minor febrile illnesses in epileptic children. Standard treatment ${ }^{10}$ includes: physical measures such as sponging designed to lower the temperature; use of antipyretic medications such as ASA or acetaminophen; and a liberal use of antibiotics to treat possible bacterial infection. Each of these measures has drawbacks.

Sponging has recently been shown to be ineffective. " As shown in our study, ASA interacts with valproic acid but has also been linked to Reye's Syndrome. ${ }^{12}$ The interaction of VPA and ASA involves displacement from plasma protein bindings sites as well as possible interference in metabolism of VPA.6.13 Phenytoin may also be displaced by ASA. 14 Concern about contaminated Tylenol\{R\} has decreased the use of this and other over-the-counter medications. 15

Treatment of fever with acetaminophen for children taking anticonvulsants appears safe. We were only able to study 11 children exposed to acetaminophen while well, however, during this study, $89 \%$ of these with a fever were exposed to antipyretics. Although our sample size is not large enough to prove concurrent safety, sufficient numbers of children appeared to be exposed to acetaminophen and each of $\mathrm{CBZ}$, VPA, and PHB to be reasonably sure of the lack of interaction. One previous study has this same conclusion. ${ }^{2}$

Our study increases concern about the use of antibiotics in children with epilepsy. Based on our experience, it would appear that when indicated amoxicillin may be safely given to children receiving $\mathrm{CBZ}$. Erythromycin should not be given to children receiving $C B Z .{ }^{16.17}$ Each of our patients treated with $\mathrm{CBZ}$ and erythromycin developed increase in $\mathrm{CBZ}$ levels which, on 3 occasions, was clinically very impressive.

Trimethoprim/sulphamethoxazole also should not be combined with CBZ. In our 2 patients, there was suggestion of displacement of $\mathrm{CBZ}$ from plasma protein binding sites with increased free levels of $\mathrm{CBZ}$. An elevated free fraction of $\mathrm{CBZ}$ has the potential to contribute to toxicityl8 even though our 2 patients remained asymptomatic. Trimethoprim/sulphamethoxazole has previously been shown to interact with DPH ${ }^{19}$ which like CBZ is similarly highly protein bound.

Thus, standard measures for treating intercurrent illness with fever may increase a child's seizures or precipitate drug toxicity. A minimum amount of intervention in intercurrent illness would seem prudent, however, it should be kept in mind that even if no other medication is administered a viral illness itself appears able to change anticonvulsant levels. In our experience, children on 4 of the 5 anticonvulsants studied had changes in serum levels induced by viral infection. These changes were clinically significant for children on PHB and $\mathrm{DPH}$ but of sufficient magnitude for the other drugs as to cause potential difficulty. There have been other case reports of viral illness either increasing or decreasing anticonvulsant levels. ${ }^{20,21}$

There are several features of the design of our study which should be kept in mind. We may not have seen all of the children during each of their illnesses in the study period. The design required parents to be suspicious of an illness, take the child's temperature and then report to us. Since the study involved extra blood levels, it is likely that some parents did not contact us for all illnesses. For those who did initiate contact it is possible that there was a bias in favor of more serious or symptomatic illness. Nonetheless, $23 \%$ of the illness episodes reported resulted in a significant change in drug levels and $13 \%$ had either clinical toxicity or increase in seizure frequency with low levels.

The second issue is the timing of serum level determination. We obtained samples on the 5th day of illness to attempt to discover both protein binding displacement (which would occur early in the illness) and metabolic interaction (which might occur later in the illness). A one month followup level was drawn to look for long lasting interactions with virus infections (such as is seen with Theophyllin22) or to confirm return to baseline. It is possible that there were other changes in drug levels not detected by this protocol.

Third, we obtained levels 2 hours post-dose because patients often travel from out of town to attend our Clinic. It may well be argued that if one is monitoring for toxic effects it may be best to monitor "peak" levels, although it may be difficult to accurately predict timing of these peaks. For drugs such as enteric coated Valproic acid a level drawn just before medication is taken may not, indeed, be a "trough" level. We recognize that trough levels may be more reproducable than 2 hour post-dose levels but have attempted to address this issue by using "repeatability coefficients" and by using each child as his own control to minimize some of the variability in timed peak level.

We obtained free serum levels for CBZ, VPA and DPH during this study. As shown in Table 1, the variability of the free level was similar to that of the total level. Free level monitoring did not appear to improve information obtained by total level monitoring except in situations in which changes in binding might be anticipated, such as the VPA-ASA or CBZtrimethoprim/sulphamethoxazole interactions. ${ }^{23}$

Our study highlights the frequency and complexity of changes in anticonvulsant medications during febrile illnesses treated with monotherapy anticonvulsants. Nearly 1/4 of our 
patients with febrile illnesses had significant changes in drug levels with $9 \%$ developing clinical toxicity. The mechanisms causing these changes including presumed metabolic interaction with viral infection, dramatic direct inhibition of $\mathrm{CBZ}$ metabolism by erythromycin and plasma protein binding displacement of CBZ by trimethoprim/sulphamethoxazole and of VPA by ASA. The frequency and complexity of these interactions suggest that children with epilepsy should be closely monitored clinically and with $\mathrm{A} / \mathrm{C}$ levels during febrile illnesses.

\section{ACKNOWLEDGEMENTS}

The authors wish to thank Mrs. Sheila Lohnes, Mrs. Ione Anderson, Edie Smith RN, Helen Miller RN, and Marsha Johnston $\mathrm{RN}$ for their time and efforts on this study.

Supported in part by the Joint Research Foundation, I.W. Killam Hospital for Children and an educational support grant from McNeil Consumer Products Company.

\section{REFERENCES}

1. Goulden KJ. Effect of febrile illness and its treatment on anticonvulsant levels in children. Can Med Assoc J 1986; 134: 1337 . 1339 .

2. Neuvonen PJ, Lehtovaara R, Bardy A, et al. Antipyretic analgesics in patients on antiepileptic drug therapy. Eur J Clin Pharmacol 1979; 15: 263-268.

3. Soldin SJ, Hill JG. Rapid micromethod for measuring anticonvulsant drugs in serum by high performance liquid chromatography. Clin Chem 1976; 22: 856-859.

4 Godolphin W, Trepanier J, Farrell K. Serum and plasma for total and free anticonvulsant analyses: Effects on EMIT and ultrafilIration devices. Ther Drug Monit 1983; 5: 319-323.

5. Bland JM, Altmann DG. Statistical methods for assessing agreement between two methods of clinical measurement. Lancet 1986; $1: 307-310$.

6. Goulden KJ, Dooley JM, Camfield PR, et al. Clinical valproate toxicity induced by acetylsalicylic acid. Neurology 1987;37: 1392-1394.

7. Dingle JH, Badger GF, Jordan WS Jr. Illness in the home. Cleveland: Case Western Reserve Univ Press, 1964.
8. Monto AS, Ullman BM. Acute respiratory illness in an American community: The Tecumseh study. JAMA 1974; 227: 164-169.

9. Bell JA, Huebner RJ, Rosen L, et al. Illness and microbial experiences of nursery school children at Junior Village. Am J Hyg $1961 ; 74: 267-292$.

10. Treating fever in your child [pamphlet]. Health Protection Branch, Health and Welfare Canada.

11. Newman J. Evaluation of sponging to reduce body temperature in febrile children. Can Med Assoc J 1985; 132: 64 I-642.

12. Remington PL, Rowley D, McGee $\mathrm{H}$, et al. Decreasing trends in Reye Syndrome and aspirin use in Michigan, 1979 to 1984. Pediatrics 1986; 77: 93-98.

13. Farrell K, Orr JM, Abbott FS, et al. The effect of acetylsalicylic acid on serum free valproate concentrations and valproate clearance in children. J Pediatr 1982; 101: 142-144.

14. Paxton JW. Effects of aspirin on salivary and serum phenytoin kinetics in healthy subjects. Clin Pharmacol Ther 1980;170. 178.

15. Dershewitz RA, Levin GS. The effect of the Tylenol scare on parent's use of over-the-counter drugs. Clin Pediatr 1983; 23: 445 448 .

16. Wroblewski BA, Singer WD, Whyte J. Carbamazepine-erythromycin interaction: Case studies and clinical significance. JAMA 1986; 255: 1165-1167.

17. Goulden KJ, Camfield PR, Dooley JM, et al. Severe carbamazepine intoxication after coadministration of erythromycin. J Pediatr 1986; 109: 135-138.

18. Riva R, Albani F, Ambrosetto G, et al. Diurnal fluctuations in free and total steady-state plasma levels of carbamazepine and correlation with intermittent side effects. Epilepsia 1984; 25: 476-481.

19. Hansen JM, Kampmann JP, Sierbaek-Nielsen K, et al. The effect of different sulphonamides on phenytoin metabolism in man Acta Med Scand (Suppl) 1979; 624: 106-110.

20. Leppik IE, Fisher J, Kriel R, et al. Altered phenytoin clearance with febrile illness. Neurology 1986; 36: 1367-1370.

21. Levine $M$, Jones $M W$. Toxic reaction to phenytoin following a viral infection [C]. Can Med Assoc J 1983; 128: 1270-1271.

22. Chang KC, Bell TD, Lauer BA, et al. Altered theophylline pharmacokinetics during acute respiratory virus illness. Lancet 1978; 1: 1132-1133.

23. Levy RH, Schmidt D. Utility of free level monitoring of antiepileptic drugs. Epilepsia 1985; 26: 199-205. 